\title{
The potential contribution of endothelin- 1 to neurovascular abnormalities in streptozotocin-diabetic rats
}

\author{
N. E. Cameron, K. C. Dines, M. A. Cotter \\ Department of Biomedical Sciences, University of Aberdeen, Scotland, UK
}

\begin{abstract}
Summary Abnormal vascular endothelium function may contribute to the reduced nerve perfusion implicated in the aetiology of neuropathy in diabetes mellitus. The aim was to test the hypothesis that a powerful vasoconstrictor, endothelin-1, could be involved in nerve dysfunction in streptozotocin-diabetic rats. After 6 weeks of untreated diabetes, rats were implanted with osmotic minipumps which continuously delivered the endothelin-1 antagonist, BQ-123, to the circulation via a jugular vein cannula. Sciatic motor conduction velocity, monitored serially, was increased after 4 days, treatment $(p=0.028)$, and reached asymptote by $9-11$ days $(p=0.0001)$, when the degree of amelioration was approximately $60 \%$ of the initial diabetic deficit. Treatment of non-diabetic rats for 13 days with $\mathrm{BQ}-123$ had no significant effect on motor conduction velocity. Sensory saphenous nerve conduction velocity was measured acutely after 20 days, BQ-123 treatment. The amelioration of a sensory deficit was approximately $80 \%(p<0.001)$;
\end{abstract}

the resultant conduction velocity value was not significantly different from that of a non-diabetic control group. After 20 days, treatment, sciatic nutritive endoneurial blood flow was measured by microelectrode polarography and hydrogen clearance. A $48 \%$ deficit with untreated diabetes $(p<0.001)$ was $64 \%$ ameliorated by BQ-123 treatment $(p<0.001)$. In non-diabetic rats, BQ-123 treatment had no effect on blood flow. We conclude that endothelin-1 does not seem to be involved in the control of nerve blood flow in non-diabetic rats; however, it makes a major contribution to the perfusion deficit in experimental diabetes. This has deleterious consequences for nerve conduction, and it is possible that endothelin-1 receptor blockade may have therapeutic potential in diabetic patients. [Diabetologia (1994) 37: 1209-1215]

Key words Neuropathy, nerve conduction, nerve blood flow, endothelin-1, vascular endothelium, hypoxia, streptozotocin, diabetic rat.
An early reduction in peripheral nerve blood flow and consequent endoneurial hypoxia $[1,2]$ in experimental diabetes mellitus leads to the rapid development of diminished nerve conduction velocity (NCV) and increased resistance to ischaemic conduc-

Received: 22 March 1994

and in revised form: 20 June 1994

Corresponding author: Dr. N. Cameron, Department of Biomedical Sciences, University of Aberdeen, Marischal College, Aberdeen AB9 1AS, Scotland, UK

Abbreviations: $\mathrm{ED}_{50}, 50 \%$ effective dose; EMG, electromyogram; ET, endothelin-1; NCV, nerve conduction velocity; NO, nitric oxide. tion failure [3, 4]. Similar subclinical functional indicators are found in newly-diagnosed diabetic patients [5, 6]. Endoneurial hypoxia and reduced blood flow are also present in patients with established neuropathy [7-9]; therefore it is likely that neurovascular effects play a major role in the aetiology of this diabetic complication.

Abnormalities of and damage to vascular endothelium contribute to diabetic microangiopathy [1016]. Thus, prostacyclin release is decreased in experimental diabetes [17] and in patients [18] because of reduced substrate availability as a consequence of impaired $\omega-6$ essential fatty acid metabolism [19, $20]$. In addition, the synthesis or action of nitric oxide (NO) is diminished [10-14], and activity in the 
coagulatory system is increased [21]. Together, these result in loss of local vasodilation, and increased thrombosis formation which contribute to nerve ischaemia [22]. Increased LDL and particularly its oxidised and glycated forms may play a major role in damaging the endothelium [23-25]. Endothelial damage and tissue hypoxia cause increased release of a third factor, the potent vasoconstrictor peptide, endothelin-1 (ET) [26, 27]. Plasma ET levels are elevated in several vascular disease states, including those in diabetic patients and rats [28-30]. Although the cardiovascular significance of elevated plasma ET is unknown, levels are probably too low to exert a profound general vascular effect. However, plasma ET is derived from an "overflow" effect, reflecting greatly enhanced synthesis at the local tissue level [27].

There is increased ET release by the endothelium of mesenteric vessels in diabetic rats [29]. If this also occurs in nerve vascular supply, the likely effect is vasoconstriction and reduced blood flow. Thus, the aim was to examine whether ET was involved in neurovascular deficits in experimental diabetes. To this end, the effect of a specific $E T_{\mathrm{A}}$ receptor antagonist on NCV and sciatic endoneurial blood flow was examined in streptozotocin-diabetic and non-diabetic rats.

\section{Materials and methods}

Male Sprague-Dawley rats (Aberdeen University breeding colony), 19 weeks old at the start of the study were used. Diabetes was induced by streptozotocin freshly dissolved in sterile $154 \mathrm{mmol} \mathrm{l}^{-1} \mathrm{NaCl}$ solution ( $40-45 \mathrm{mg} \cdot \mathrm{kg}^{-1}$ i.p.), and was verified $24 \mathrm{~h}$ later by estimating hyperglycaemia and glycosuria (Visidex II and Diastix; Ames, Slough, Bucks., UK). Animals were tested weekly, and weighed daily. They were rejected if blood glucose was less than $20 \mathrm{mmol}^{-1}$ or if they showed a consistent increase in body weight over 3 days. Samples for plasma glucose measurement using a standard test kit (GODPerid method; Boehringer Mannheim, Mannheim, Germany) were taken on the day of final experiments.

After 6 weeks of untreated diabetes, rats were implanted subcutaneously with osmotic minipumps (Alzet 2ML2, Alza Corp., Palo Alto, Calif., USA) filled with the selective $\mathrm{ET}_{\mathrm{A}}$ antagonist BQ-123 (Berlex, Richmond, Calif., USA), cyclo (-DTrp-D-Asp-Pro-D-Val-Leu), dissolved in sterile phosphate buffered $\mathrm{NaCl}$ solution $\left(154 \mathrm{mmol} \cdot \mathrm{l}^{-1}, \mathrm{pH} \mathrm{7.35)}\right.$. Output of the pump was fed to a cannula inserted in the jugular vein. Rats were treated for up to 20 days with a dose of BQ-123 of approximately $0.7 \mathrm{mg} \cdot \mathrm{kg}^{-1} \mathrm{day}^{-1}$. The dose was governed by the pump delivery rate and the maximum solubility of $\mathrm{BQ}$ 123. In acute experiments on anaesthetized rats, infusion of BQ-123 at a dose 10-20 times less than that used in this investigation substantially $(67 \%)$ attenuated the pressor response to ET infusion [31]. Thus, a high level of chronic $\mathrm{ET}_{\mathrm{A}}$ receptor blockade would be expected at the dose employed. Osmotic minipumps were replaced at 14 days. A separate group of non-diabetic rats was also implanted with BQ-123-containing osmotic minipumps, delivering a similar dose to that used for diabetic rats.
The day before pump implantation in the diabetic group, $\mathrm{NCV}$ in the sciatic branch to tibialis anterior muscle was measured to establish baseline values using a previously described method [32]. Briefly, under halothane anaesthesia (2-5\% in air), sterile bipolar needle stimulating electrodes $(2 \mathrm{~mm}$ separation of tips) were inserted through the skin to stimulate sciatic nerve at the sciatic notch and popliteal fossa. A sterile concentric bipolar recording electrode was inserted into tibialis anterior muscle. Leg skin temperature was kept in the range $36-38^{\circ} \mathrm{C}$ by radiant heat. EMGs evoked from both stimulation sites were averaged eight times and latencies of the first inflections were measured. The sciatic nerve between the two stimulating electrodes takes a fairly straight course, and interelectrode distances were used to calculate NCV.

Serial measures of NCV were made in this treated diabetic group every 2 or 3 days for 18 days to examine the time course of NCV correction. In final experiments (day 20), saphenous sensory NCV was measured as previously described [33]. $\mathrm{Pa}$ tency of the jugular cannulae was also tested in final experi ments, by connecting a syringe, filled with sterile $\mathrm{NaCl}$ solution $\left(154 \mathrm{mmol} \cdot \mathrm{l}^{-1}\right)$, in place of the osmotic minipump. If moderate pressure applied to the syringe plunger did not result in free flow into the jugular vein, the cannula was considered blocked. This was an a priori criterion for acceptance of data. Thirteen rats were implanted at the start of the NCV study. Of these, 1 died and of the remaining 12 rats surviving the full experimental period, 2 proved to have blocked cannulae and NCV results from these rats were excluded.

For groups of diabetic $(n=9)$ and non-diabetic $(n=12)$ rats given BQ-123 treatment, blood flow was determined after 20 and 12-14 days, respectively. There were no losses due to blocked cannulae in these groups. Before blood flow measurement, for the non-diabetic group, sciatic NCV to tibialis anterior muscle in the contralateral leg was determined. In addition to these groups, separate untreated non-diabetic and diabetic rats were used to give reference values for NCV and blood flow.

Nerve blood flow was measured by microelectrode hydrogen polarography as previously described $[1,2]$. In final experiments, rats were anaesthetized with inactin $\left(50-100 \mathrm{mg} \mathrm{kg}^{-1}\right.$ i.p.), the trachea was cannulated for artificial ventilation and a carotid cannula was used to monitor mean systemic blood pressure. Core temperature of the animal was monitored and regulated between $37^{\circ}$ and $38^{\circ} \mathrm{C}$, using a rectal probe and radiant heat. The skin around the sciatic nerve incision was sutured to a metal ring and used to form a pool which was filled with li quid paraffin at $37^{\circ} \mathrm{C}$ to a depth of at least $1 \mathrm{~cm}$ to minimise diffusion of gases directly to or from the nerve. Rats were given neuromuscular blockade using d-tubocurarine (Sigma, 2 $\mathrm{mg} \cdot \mathrm{kg}^{-1}$ via the carotid cannula) and artificially ventilated. The level of anaesthesia was monitored by observing any reaction of blood pressure to manipulation, and supplementary inactin was given as necessary. Briefly, a glass-insulated platinum microelectrode (tip diameter $2-8 \mu \mathrm{m}$ ) was inserted into the middle portion of the sciatic nerve, above its trifurcation, and polarized at $0.25 \mathrm{~V}$ with respect to a reference electrode inserted subcutaneously in the flank of the rat. $10 \% \mathrm{H}_{2}$ was added to the inspired gas, the proportions of $\mathrm{O}_{2}$ and $\mathrm{N}_{2}$ being adjusted to $20 \%$ and $70 \%$, respectively. When the $\mathrm{H}_{2}$ current recorded by the electrode had stabilized (20-30 min), indicating equilibrium with arterial blood, the $\mathrm{H}_{2}$ supply was shut off and $\mathrm{N}_{2}$ delivery was increased appropriately. The $\mathrm{H}_{2}$ clearance curve was recorded until baseline $(30 \mathrm{~min}-1 \mathrm{~h})$, the latter being defined as no systematic decline in electrode current over $5 \mathrm{~min}$. This procedure was then repeated at another nerve site. After the experiment, clearance curves were digitized and mono- or bi-exponential curves were fitted to the 


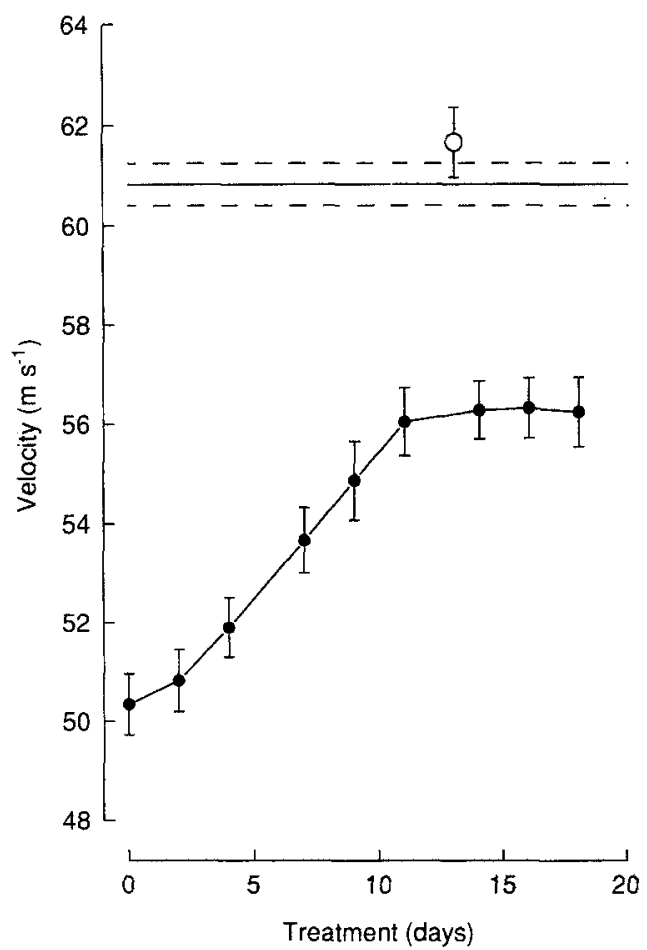

Fig. 1. Serial measurements of the effects of ET antagonist treatment on sciatic motor conduction velocity following 6 weeks of untreated diabetes. BQ-123 treated diabetic rats (O), $n=10$; non-diabetic rats treated for 13 days $(\bigcirc), n=12$. Horizontal solid line flanked by dashed lines, mean \pm SEM for a group of untreated non-diabetic rats, $n=10$. All data are mean \pm SEM. Statistics: NCV in diabetic rats was significantly improved by treatment from day 4 ( $p=0.028$ vs baseline value on day 0 ) onwards. Asymptote was reached by day 11 $(p<0.0001$ vs baseline), but NCV was reduced compared to the untreated non-diabetic group ( $p=0.001)$

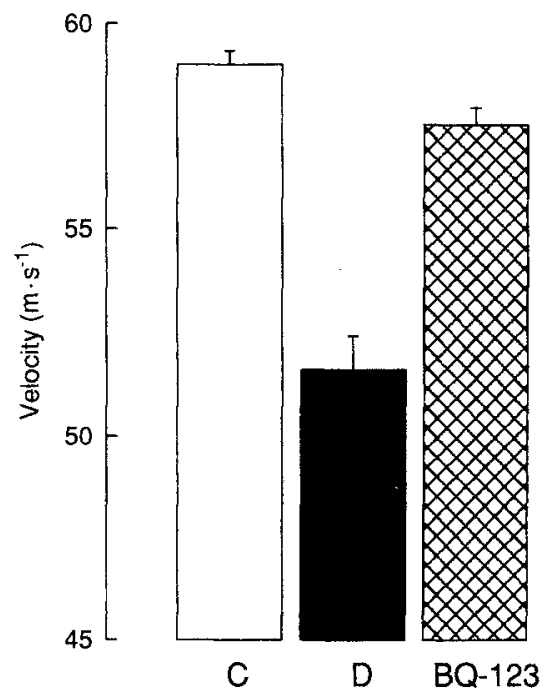

Fig. 2. Effects of ET antagonist treatment on sensory saphenous nerve conduction velocity following 6 weeks of untreated diabetes. C, non-diabetic control group, $n=12 ; \mathrm{D}$, untreated 2-month diabetic group, $n=11$; BQ-123, 20-day ET antagonist-treated diabetic group, $n=10$. All data are mean + SEM. Statistics: C vs D, $p<0.001 ;$ C vs BQ-123, NS; D vs $\mathrm{BQ}-123, p<0.001$ data by computer using appropriate non-linear regression software that employed the Marquardt algorithm and the least squares method for optimising goodness-of-fit (Inplot; Graphpad, San Diego, Calif., USA). The slow exponent, representing nutritive flow [34], was accepted. The average of the two determinations was taken to represent sciatic endoneurial blood flow. Vascular conductance was calculated by dividing blood flow by mean arterial blood pressure during the recording period.

\section{Statistical analysis}

Data are expressed as mean \pm SEM. One-way analysis of variance was performed, followed by Student-Newman-Keuls tests to correct for multiple comparisons and assign differences to individual between-group comparisons when overall significance $(p<0.05)$ was attained. Paired Student's $t$-tests were used to assess the significance of within-rat changes for serial measurement of motor NCV and unpaired Student's $t$-tests were used for comparison with a non-diabetic control group.

\section{Results}

Diabetic rats were hyperglycaemic, with a plasma glucose concentration of $41.7 \pm 2.3 \mathrm{mmol}^{-1} \mathrm{l}^{-1}$ and showed a weight loss from $473 \pm 14$ to $333 \pm 13 \mathrm{~g}$. There was no effect of BQ-123 treatment on these parameters (plasma glucose $44.1 \pm 1.6 \mathrm{mmol} \cdot \mathrm{l}^{-1}$, weight loss from $476 \pm 8$ to $338 \pm 18 \mathrm{~g}$ ). BQ-123 also had no effect on non-diabetic rats; plasma glucose was $8.8 \pm 0.6 \mathrm{mmol} \cdot \mathrm{l}^{-1}$ and weight changed from $466 \pm 9$ to $477 \pm 9 \mathrm{~g}$ over the 13-day treatment period.

Figure 1 shows the motor NCV changes with increasing duration of $\mathrm{BQ}-123$ treatment. Compared to the baseline value following 6 weeks of untreated diabetes (day 0 ), there was a progressive increase in NCV which reached asymptote after 9-11 days. The amelioration for days 14-18 was approximately $60 \%$ $(p<0.0001)$. BQ-123 treatment for 13 days had no significant effect on NCV in non-diabetic rats.

Data from sensory saphenous NCV determinations are shown in Figure 2. There was a $12.5 \pm 1.4 \%$ deficit after 2 months of untreated diabetes. BQ-123 treatment for the last 20 days reduced the deficit to $2.5 \pm 0.7 \%(p<0.001)$, which was not significantly different from the non-diabetic control value.

Endoneurial blood flow (Fig. $3 \mathrm{~A}$ ) was $48 \%$ reduced by 2 months of untreated diabetes $(p<0.001)$. Treatment with BQ-123 had no significant effect in non-diabetic rats; however, with diabetes there was a significant $(p<0.001)$ improvement in blood flow which corresponded to a $63.5 \pm 9.1 \%$ correction of the deficit. There were variations in blood pressure (Fig.3B) between groups, with pressures generally being lower for diabetes. This was not statistically significant for untreated diabetes; however, the lowest pressure was seen in the BQ-123 treated diabetic group $(p<0.001)$. BQ-123 treatment did not have a 

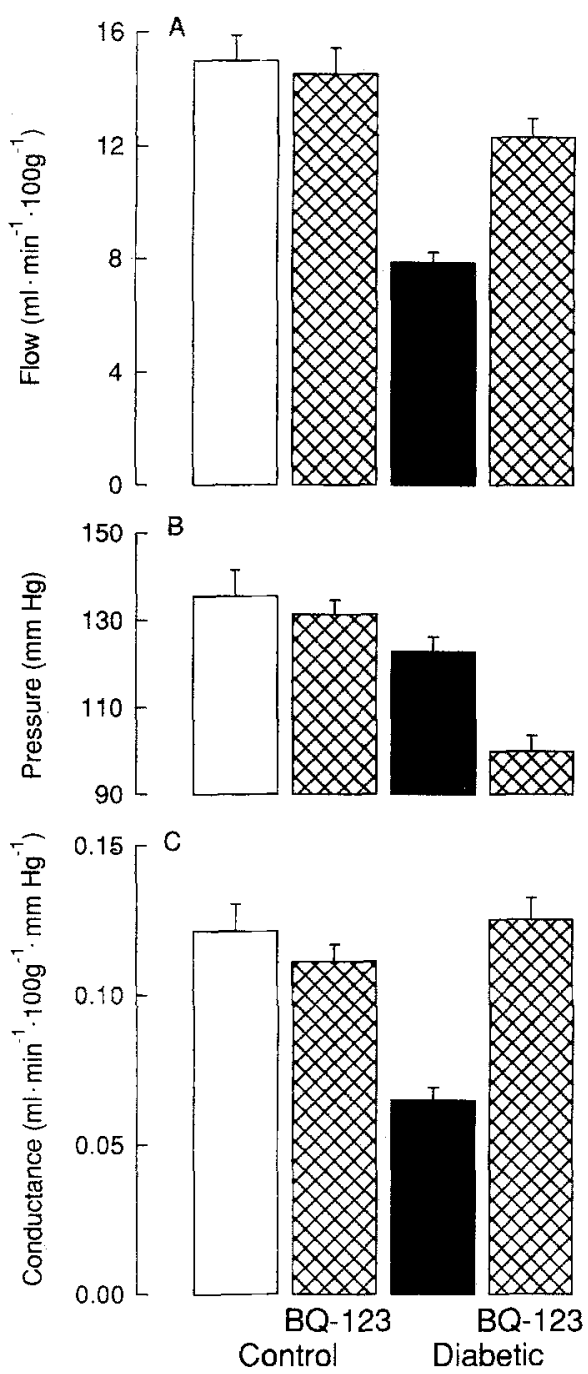

Fig.3. (A-C) Nutritive endoneurial blood flow (A), mean systemic arterial pressure (B) and nutritive endoneurial vascular conductance (C) in non-diabetic and diabetic rats with and without ET antagonist treatment. All data are group means + SEM. Control groups, untreated, $n=10 ; \mathrm{BQ}-123$ treated for 13 days, $n=12$. Diabetic groups, 2-month untreated, $n=16$; $\mathrm{BQ}-123$ treated for 20 days following 6 weeks of untreated diabetes, $n=9$. Statistics: Control vs Control + BQ-123, NS for all measurements; blood flow, Control vs Diabetic untreated, $p<0.001$; Control vs Diabetic + BQ123, $p<0.01$; Diabetic vs Diabetic + BQ-123, $p<0.001$; blood pressure; all comparisons NS except for Diabetic $+\mathrm{BQ}-123$ vs Control, Control + BQ-123 or Diabetic groups, $p<0.001$; vascular conductance, Control vis Diabetic untreated, $p<0.001$; Control vs Diabetic + BQ-123, NS; Diabetic vs Diabetic + BQ-123, $p<0.001$; Control + BQ-123 vs Diabetic + BQ123, NS

hypotensive effect in non-diabetic rats. When the data were expressed in terms of vascular conductance (Fig. 3C), thus compensating for blood pressure differences, there was complete normalization of conductance with BQ-123 treatment in diabetic rats $(p<0.001$ vs untreated diabetic group, NS vs control group). In contrast, BQ-123 had no significant effect on sciatic vascular conductance in non-diabetic rats.

\section{Discussion}

These data provide the first demonstration that blockade of $\mathrm{ET}_{\mathrm{A}}$ receptors in streptozotocin-diabetic rats produces a marked improvement in motor and sensory nerve function. In common with other vasoactive treatments that return NCV to normal, the functional improvement parallels an increase in nutritive blood flow $[2,35]$. In addition to conventional vasodilators, similar findings apply to agents that act on some of the metabolic consequences of diabetes and hyperglycaemia, such as aldose reductase inhibitors [36, 37], aminoguanidine [38], anti-oxidants [39] $\omega-6$ essential fatty acids [40] and insulin [41]. Thus, it is likely that hyperglycaemia causes vascular dysfunction which in turn leads to nerve abnormalities.

Previous work on vessel function has highlighted the importance of endothelial abnormalities in the aetiology of diabetic microvascular disease. Thus, endothelium-dependent relaxation by $\mathrm{NO}$ is reduced [1014] and there may be increases in endothelium-dependent contracting factors $[14,15]$. Prostacyclin synthesis is attenuated $[17,18]$ and the thrombolytic system is also impaired [21]. These alterations favour vasoconstriction, platelet aggregation, adhesion to the endothelium and thrombosis. Other changes, such as increased local production of angiotensin II, would further favour vasoconstriction [35] and the smooth muscle proliferation involved in atherogenesis [42].

The data for BQ-123 treatment are in accord with this generalized view of endothelial dysfunction. An increase in plasma ET levels and evidence of local enhancements of tissue activity are associated with some cardiovascular disease states including diabetes [26-29]. ET gene expression is also increased by diabetes, particularly in patients with peripheral vasculopathy [30]. There are several potential stimuli for increased ET synthesis and release, such as endothelial damage and hypoxia [27]. In addition, at least in cultured endothelial cells, high glucose levels enhance ET secretion [43]. Diabetic vessels have reduced ET sensitivity [44 46], perhaps caused by a down-regulation of receptors $[47,48]$ or transduction mechanisms [49] in response to chronic exposure. Regional blood flow patterns for bolus ET injection are altered by diabetes in conscious rats $[10,50]$ but the changes are complex, suggesting tissue heterogeneity. Thus, for renal and mesenteric vascular beds, where flow is increased by diabetes, ET-mediated vasoconstriction was increased. However, in the hindlimb circulation, where flow decreases with diabetes, the vasoconstrictor response was relatively muted [50]. The data for sciatic nerve agree with the latter finding, as the effects of BQ-123 suggest that there would already be much greater local ET production and vasoconstriction with diabetes.

In non-diabetic rats, sciatic nerve segmental vascular supply is sensitive to acute exogenous ET adminis- 
tration, which causes a sufficiently powerful vasoconstriction to transiently impair neuronal function [51]. The present data are the first to show that chronic BQ-123 treatment improved the reduced nutritive blood flow and vascular conductance associated with experimental diabetes. Vascular conductance was within the non-diabetic range; however, blood flow remained somewhat subnormal because blood pressure was lower in treated than untreated diabetic rats, which would be expected as vasa nervorum shows minimal pressure autoregulatory responses [52]. In marked contrast, BQ-123 had no effect on blood flow, vascular conductance or blood pressure in non-diabetic rats. This is contrary to the findings for some other vasodilators, such as those blocking the sympathetic noradrenergic system [53] or nitrovasodilators [54], which increase nerve blood flow in non-diabetic rats, although a similar lack of effect on nerve perfusion was found for an angiotensin II antagonist [35]. Thus, the data suggest that $\mathrm{ET}_{\mathrm{A}}$-receptor-mediated effects do not normally play a major role in the control of (resting) vasa nervorum blood flow, and probably blood pressure. However, with diabetes, basal ET release had a significant influence on both nerve perfusion and blood pressure. While this data provides evidence for the "classic" vasoconstriction effect of $\mathrm{ET}_{\mathrm{A}}$ receptor activation $[10,27]$ on vasa nervorum, it is not known if there are additional effects mediated by $\mathrm{ET}_{\mathrm{B}}$ receptors in diabetes. A test of this notion awaits the development of specific $\mathrm{ET}_{\mathrm{B}}$ antagonists.

The sciatic motor NCV amelioration by BQ-123, in percentage terms, matched that for blood flow rather than vascular conductance. Treatments that completely return nutritive blood flow to the non-diabetic range, such as guanethidine or aldose reductase inhibition, also completely restore sciatic motor NCV $[2$, 36]. This suggests that the hypotensive effect of BQ123 seen in anaesthetized diabetic rats was probably also present when they were conscious. Otherwise, based on the conductance data, a greater NCV amelioration would be expected. Compared to sciatic motor fibres, saphenous sensory fibres showed a greater NCV response to BQ-123. We have previously noted this trend from other studies, for example using aldose reductase inhibitors, where the degree of amelioration was greater for a given dose [33] and the $\mathrm{ED}_{50}$ for saphenous was lower than for sciatic nerve [36]. Thus, it may be that the vascular supply of the relatively small saphenous nerve has a greater safety margin than that of the major sciatic trunk.

Sciatic nerve endoneurium is hypoxic in experimental diabetes $[1,36,39]$, as is the sural nerve in neuropathic patients [7]. This provides one potential stimulus for endothelial ET synthesis and release [27]. Hypoxia enhances oxidative stress which directly affects neurons [55]. A high level of oxygen free radicals causes lipid peroxidation which inhibits prosta- cyclin synthesis [56]. The ability of resistance vessels to relax is further impaired as oxygen free radicals react with NO [57], preventing the stimulation of smooth muscle guanylate cyclase. Reaction products, such as the hydroxyl radical [58] can damage endothelial cells directly. Cytotoxic effects of oxidised LDL on the endothelium have also been noted [24, 25]. Damage to endothelial cells is a further stimulus for ET release [27]. Thus, there may be an element of positive feedback, involving a cycle of oxidative stress, hypoxic damage, endothelial dysfunction and vasoconstriction which maintains reduced nerve perfusion in experimental diabetes. Blocking any element of this self-reinforcing cycle could potentially restore blood flow. It is of interest that treatment with oxygen free radical scavengers improves nerve conduction $[39,59]$, nutritive blood flow [39], endothelium-dependent relaxation [60] and protects against the development of markers of endothelial damage such as increased plasma angiotensin converting enzyme concentration [39]. Thus, it is plausible that anti-oxidant treatment would also reduce local and circulating ET levels.

Elevated ET production in diabetes may also be important for other aspects of neurovascular function. Thus, in non-diabetic rats ET causes increased vascular permeability [61], which is greatly exacerbated when NO synthase activity is also blocked [62]. Many treatments that normalise NCV in diabetic rats also improve blood flow, which would reduce nerve hypoxia and, therefore, minimise at least one potential stimulus for local ET production. Such agents include aldose reductase inhibitors, anti-oxidants and aminoguanidine [36-39,63]. They also prevent or correct increases in vascular albumin permeation [64], therefore, it is plausible that their common actions on nerve function, blood flow and albumin permeation arise because they all protect against endothelial dysfunction, damage and consequent ET release $[12-14,16,38,39,60]$. The efficacy of these treatments would be further increased by their ability to counteract impaired NO action $[13,14,35,59$, $65]$.

In conclusion, evidence increasingly identifies abnormalities of the vascular endothelium as an important cause of impaired nerve perfusion and neuronal dysfunction in experimental diabetes. Parallels may also be drawn with neurovascular changes in diabetic patients. Thus, ET is probably one of the important contributory factors to the multiple aetiology of diabetic microangiopathy and $\mathrm{ET}_{\mathrm{A}}$ antagonists may have a potential therapeutic role for complications like neuropathy.

Acknowledgements. NEC is supported by a Wellcome Trust Research Leave Fellowship. KCD is supported by a Research Studentship from Scotia Pharmaceuticals. We thank Drs. Rubanyi and Polokoff of Berlex Biosciences for supplying BQ123 and some financial support for materials. 


\section{References}

1. Tuck RR, Schmelzer JD, Low PA (1984) Endoneurial blood flow and oxygen tension in the sciatic nerves of rats with experimental diabetic neuropathy. Brain 107: 935-950

2. Cameron NE, Cotter MA, Low PA (1991) Nerve blood flow in early experimental diabetes in rats: relation to conduction deficits. Am J Physiol 261: E1-E8

3. Eliasson SG (1964) Nerve conduction changes in experimental diabetes. J Clin Invest 43: 2352-2358

4. Seneviratne KN, Peiris OA (1969) The effects of hypoxia on the excitability of isolated peripheral nerves of alloxandiabetic rats. J Neurol Neurosurg Psychiatry 32: 462-469

5. Gregerson G (1967) Diabetic neuropathy: influence of age, sex, metabolic control and duration of diabetes on motor conduction velocity. Neurology 17: 972-980

6. Ward JD, Barnes CG, Fisher DJ, Jessop JD, Baker RWR (1971) Improvement in nerve conduction following treatment in newly-diagnosed diabetics. Lancet I: 428-431

7. Newrick PG, Wilson AJ, Jakubowski J, Boulton AJM, Ward JD (1986) Sural nerve oxygen tension in diabetes. BMJ 293: 1053-1054

8. Young MJ, Veves A, Walker MG, Boulton AJM (1992) Correlations between nerve function and tissue oxygenation in diabetic patients: further clues to the aetiology of diabetic neuropathy? Diabetologia 35: 1146-1150

9. Tesfaye S, Harris N, Jakubowski JJ, Mody C, Wilson RM, Rennie IG, Ward JD (1993) Impaired blood flow and arterio-venous shunting in human diabetic neuropathy: a novel technique of nerve photography and fluorescein angiography. Diabetologia 36: 1266-1274

10. Tomlinson KC, Gardiner SM, Hebden RA, Bennett T (1992) Functional consequences of streptozotocin-induced diabetes mellitus, with particular reference to the cardiovascular system. Pharmacol Rev 44: 103-150

11. Oyama Y, Kawasaki H, Hattori Y, Kanno M (1986) Attenuation of endothelium-dependent relaxation in aorta from diabetic rats. Eur J Pharmacol 131: 75-78

12. Peiper GM, Gross GJ (1988) Oxygen free radicals abolish endothelium-dependent relaxation in diabetic rat aorta. Am J Physiol 255: H825-H833

13. Cameron NE, Cotter MA (1992) Impaired contraction and relaxation in aorta from streptozotocin-diabetic rats: role of polyol pathway activity. Diabetologia 35: 1011-1019

14. Tesfamariam B, Cohen RA (1992) Free radicals mediate endothelial cell dysfunction caused by elevated glucose. Am J Physiol 263: H321-H326

15. Mahan WG (1989) Impairment of endothelium-dependent dilation of cerebral arterioles during diabetes mellitus. Am J Physiol 256: H621-H625

16. Lin S-J, Hong C-Y, Chang M-S, Chiang BN, Chien S (1993) Increased aortic endothelial cell death and enhanced transendothelial macromolecular transport in streptozotocindiabetic rats. Diabetologia 36: 926-930

17. Ward KK, Low PA, Schmelzer JD, Zochodne DW (1989) Prostacyclin and noradrenaline in peripheral nerve of chronic experimental diabetes in rats. Brain 112: 197-208

18. Brunkwall JS, Bergqvist D (1992) Prostacyclin release from the human saphenous vein in diabetics is lower than in nondiabetics. World J Surg 16: 1141-1146

19. Cameron NE, Cotter MA, Robertson S (1991) Effects of essential fatty acid dietary supplementation on peripheral nerve and skeletal muscle function and capillarisation in streptozotocin diabetic rats. Diabetes 40: 532-539

20. Dines KC, Cotter MA, Cameron NE (1993) Contrasting effects of treatment with $\omega-3$ and $\omega-6$ essential fatty acids on peripheral nerve function and capillarization in streptozotocin-diabetic rats. Diabetologia 36: 1132-1138
21. Ceriello A (1993) Coagulation activation in diabetes mellitus: the role of hyperglycaemia and therapeutic prospects. Diabetologia 36: 1119-1125

22. Cameron NE, Cotter MA, Dines KC, Maxfield EK (1993) Pharmacological manipulation of vascular endothelium in non-diabetic and streptozotocin-diabetic rats: effects on nerve conduction, hypoxic resistance and endoneurial capillarization. Diabetologia 36: 516-522

23. Picard S, Parthasarathy S, Fruebis J, Witztum JL (1992) Aminoguanidine inhibits oxidative modification of low density lipoprotein protein and the subsequent increase in uptake by the macrophage scavenger receptor. Proc Natl Acad Sci USA 89: 6876-6880

24. Morel DW, Chisolm G (1989) Antioxidant treatment of diabetic rats inhibits lipoprotein oxidation and cytotoxicity. J Lipid Res 30: 1827-1834

25. Evensen SA, Galdal KS, Nilsen E (1983) LDL-induced cytotoxicity and its inhibition by anti-oxidant treatment in cultured human endothelial cells and fibroblasts. Atherosclerosis 49: 23-30

26. Vane JR, Änggård EA, Botting RM (1990) Regulatory functions of the vascular endothelium. New Engl J Med 323: 27-36

27. Simonsen MS (1993) Endothelins: multifunctional renal peptides. Physiol Rev 78: 375-411

28. Takahashi K, Ghatei MA, Lam H-C, O'Halloran DJ, Bloom SR (1990) Elevated plasma endothelin levels in patients with diabetes mellitus. Diabetologia 33: 306-310

29. Takeda Y, Miyamori I, Yoneda T, Takeda R (1991) Production of endothelin-1 from the mesenteric arteries of streptozotocin-induced diabetic rats. Life Sci 48: 2553-2556

30. Derwahl M, Schmermund A, Hamacher C, Schifferdecker E, Schatz H (1993) Expression of endothelin 1 in diabetics with peripheral vascular disease. Diabetologia 36 [Suppl 1]: A203 (Abstract)

31. Warner TD, Allcock GH, Vane JR (1994) Reversal of established responses to endothelin- 1 in vivo and in vitro by the endothelin receptor antagonists, BQ-123 and PD 145065. Br J Pharmacol 112: 207-213

32. Cameron NE, Cotter MA, Robertson S, Maxfield EK (1993) Nerve function in experimental diabetes in rats: effects of electrical activation. Am J Physiol 264: E161-E166

33. Cameron NE, Cotter MA, Robertson S (1989) The effect of aldose reductase inhibition on the pattern of nerve conduction deficits in diabetic rats. Q J Exp Physiol 74: 917 926

34. Day TJ, Lagerlund TD, Low PA (1989) Analysis of $\mathrm{H}_{2}$ clearance curves used to measure blood flow in rat sciatic nerve. J Physiol 414: 35-54

35. Maxfield EK, Cameron NE, Cotter MA, Dines KC (1993) Angiotensin II receptor blockade improves nerve function, modulates nerve blood flow and stimulates endoneurial angiogenesis in streptozotocin-diabetic rats. Diabetologia 36: $1230-1237$

36. Cameron NE, Cotter MA, Dines KC, Maxfield EK (1993) Effects of aldose reductase inhibition on nerve blood flow and oxygen tension in diabetic rats. Diabetologia 36 [Suppl 1]: A199 (Abstract)

37. Hotta N, Kakuta H, Koh $\mathrm{N}$ et al. (1992) Effect of a new potent aldose reductase inhibitor, "TAT" on diabetic neuropathy of rats. Diabetologia 35 [Suppl 1]: A151 (Abstract)

38. Kihara M, Schmelzer JD, Poduslo JF, Curran FF, Nickander KK, Low PA (1991) Aminoguanidine effect on nerve blood flow, vascular permeability, electrophysiology, and oxygen free radicals. Proc Natl Acad Sci USA 88: $6107-$ 6111

39. Cameron NE, Cotter MA, Archibald V, Dines KC, Maxfield EK (1994) Anti-oxidant and pro-oxidant effects on 
nerve conduction velocity, endoneurial blood flow and oxygen tension in non-diabetic and streptozotocin-diabetic rats. Diabetologia 37: 449-459

40. Cotter MA, Dines KC, Cameron NE (1993) Comparison of the effects of evening primrose oil and the putative active triglyceride, di-linolein mono- $\gamma$-linolenate (DLMG), on sciatic nerve conduction velocity in diabetic rats: dose-response relationship and modulation of endoneurial blood flow. Diabet Med 10 [Suppl 3]: P67 (Abstract)

41. Stevens EJ, Carrington AL, Tomlinson DR (1993) Nerve ischaemia in experimental diabetes. Diabetologia 36 [Suppl 1]: A57 (Abstract)

42. Dzau VJ, Gibbons GH, Pratt RE (1992) Molecular mechanism of vascular renin-angiotensin system in myo-intimal hyperplasia. Hypertension 18 [Suppl II]: 100-105

43. Yamauchi T, Ohnaka K, Takayanagi R, Umeda F, Nawata H (1990) Enhanced secretion of endothelin-1 by elevated glucose levels from cultured bovine aortic endothelial cells. FEBS Lett 267: 16-18

44. Fulton DJR, Hodgson WC, Sikorski BW, King RG (1991) Attenuated responses to endothelin-1, $\mathrm{KCl}$ and $\mathrm{CaCl}_{2}$, but not noradrenaline, of aortae from rats with streptozotocininduced diabetes mellitus. Br J Pharmacol 104: 928-932

45. Hodgson WC, King RG (1992) Effect of glucose, insulin or aldose reductase inhibition on responses to endothelin-1 of aortic rings from streptozotocin-induced diabetic rats. $\mathrm{Br} \mathrm{J}$ Pharmacol 106: 644-649

46. Lawrence E, Brain SD (1992) Altered microvascular reactivity to endothelin-1, endothelin- 3 and $\mathrm{N}^{\mathrm{G}}$-nitro-L-arginine methyl ester in streptozotocin-induced diabetes mellitus. Br J Pharmacol 106: 1035-1040

47. Nayler WG, Liu J, Panagiotopoulos S, Casley DJ (1989) Streptozotocin-induced diabetes reduces the density of $\left[{ }^{125} \mathrm{I}\right]$-endothelin-binding sites in rat cardiac membranes. Br J Pharmacol 97: 993-995

48. Awazu M, Parker RE, Harvie BR, Ichikawa I, Kon V (1991) Down-regulation of endothelin-1 receptors by protein kinase $\mathrm{C}$ in streptozotocin diabetic rats. J Cardiovasc Pharmacol 17 [Suppl 7]: S500-S502

49. Chakravarthy U, McGinty A, McKillop J, Anderson P, Archer DB, Trimble ER (1994) Altered endothelin-1 induced contraction and second messenger generation in bovine retinal microvascular pericytes cultured in high glucose medium. Diabetologia 37: 36-42

50. Kiff RJ, Gardiner SM, Compton AM, Bennett T (1991) The effects of endothelin-1 and $\mathrm{N}^{\mathrm{G}}$-nitro-L-arginemethyl ester on regional haemodynamics in conscious rats with streptozotocin-induced diabetes mellitus. Br J Pharmacol 103: $1321-1326$

51. Zochodne DW, Ho LT, Gross PM (1992) Acute endoneurial ischemia induced by epineurial endothelin in the rat sciatic nerve. Am J Physiol 263: H1806-H1810

52. Low PA, Lagerlund TD, McManis PG (1989) Nerve blood flow and oxygen delivery in normal, diabetic and ischemic neuropathy. Int Rev Neurobiol 31: 355-438
53. Zochodne DW, Huang Z, Ward K, Low PA (1990) Guanethidine adrenergic sympathectomy augments endoneurial perfusion and lowers endoneurial microvascular resistance. Brain Res 519: 112-117

54. Cotter MA, Cameron NE (1994) Nitrovasodilator treatment improves sciatic nerve blood flow and attenuates the development of conduction velocity deficits in diabetic rats. Eur J Clin Invest 24 [Suppl 2]: A48 (Abstract)

55. Low PA, Nickander KK (1991) Oxygen free radical effects in sciatic nerve in experimental diabetes. Diabetes 40 : 873-877

56. Moncada S, Gryglewski RJ, Bunting S, Vane JR (1976) A lipid peroxide inhibits the enzyme in blood vessel microsomes that generates from prostaglandin endoperoxides the substance (prostaglandin X) which prevents platelet aggregation. Prostaglandins 12: 715-737

57. Gryglewski RJ, Palmer RMJ, Moncado S (1986) Superoxide anion is involved in the breakdown of endothelium-derived vascular relaxing factor. Nature 320: 454-456

58. Beckman JS, Beckman TW, Chen J, Marshall PA, Freeman BA (1990) Apparent hydroxyl radical production by peroxynitrite: implications for endothelial injury from nitric oxide and superoxide. Proc Natl Acad Sci USA 87: 16201624

59. Cameron NE, Cotter MA, Maxfield EK (1993) Antioxidant treatment prevents the development of peripheral nerve dysfunction in streptozotocin-diabetic rats. Diabetologia 36: 299-304

60. Pieper GM, Mei DA, Langenstroer P, O,Rourke ST (1992) Bioassay of endothelium-derived relaxing factor in diabetic rat aorta. Am J Physiol 263: H676-H680

61. Filep JG, Sirois MG, Rousseau A, Fournier A, Sirois P (1991) Effect of endothelin-1 on vascular permeability in the conscious rat: interactions with platelet-activating factor. Br J Pharmacol 104: 797-804

62. Filep JG, Földes-Filip E, Rousseau A, Sirois P, Fournier A (1993) Vascular responses to endothelin-1 following inhibition of nitric oxide synthesis in the conscious rat. Br J Pharmacol 110: 1213-1221

63. Cameron NE, Cotter MA (1993) Potential therapeutic approaches to the treatment or prevention of diabetic neuropathy: evidence from experimental studies. Diabet Med 10: 593-605

64. Williamson JR, Chang K, Frangos M et al. (1993) Hyperglycemic pseudohypoxia and diabetic complications. Diabetes 42: 801-813

65. Bucala R, Tracey KJ, Cerami A (1991) Advanced glycosylation products quench nitric oxide and mediate defective endothelium-dependent vasodilation in experimental diabetes. J Clin Invest 87: 432-438 